OPEN ACCESS

Edited by:

Leonard Wee

Maastro Clinic, Netherlands

Reviewed by:

Natasha A Jain,

Deaconess Henderson Clinic,

United States

Hina Khan,

Brown University, United States

Akin Atmaca,

Krankenhaus Nordwest, Germany

${ }^{*}$ Correspondence:

Caicun Zhou

caicunzhoudr@163.com

Specialty section:

This article was submitted to

Thoracic Oncology,

a section of the journal

Frontiers in Oncology

Received: 13 August 2021 Accepted: 01 November 2021 Published: 25 November 2021

Citation:

Xiong A, Wang J and Zhou C (2021) Immunotherapy in the First-Line

Treatment of NSCLC: Current Status and Future Directions in China.

Front. Oncol. 11:757993. doi: 10.3389/fonc.2021.757993

\section{Immunotherapy in the First-Line Treatment of NSCLC: Current Status and Future Directions in China}

\author{
Anwen Xiong ${ }^{1}$, Jiali Wang ${ }^{2}$ and Caicun Zhou ${ }^{3 *}$ \\ ${ }^{1}$ Department of Medical Oncology, Shanghai Pulmonary Hospital, Thoracic Cancer Institute, Tongji University School of \\ Medicine, Shanghai, China, ${ }^{2}$ Medical Research Lab (MRL) Global Medical Affairs, MSD China, Shanghai, China, \\ ${ }^{3}$ Department of Medical Oncology, Shanghai Pulmonary Hospital, Tongji University School of Medicine, Shanghai, China
}

Lung cancer causes significant morbidity and mortality in China and worldwide. In China, lung cancer accounts for nearly one-fourth of all cancer deaths. Non-small cell lung cancer (NSCLC) is the predominant type of lung cancer, accounting for approximately $80 \%-85 \%$ of all lung cancer cases. Immunotherapy with immune checkpoint inhibitors (ICls) is revolutionizing the treatment of NSCLC. Immune checkpoint molecules, including PD-1/ PD-L1 and CTLA-4, can suppress immune responses by delivering negative signals to $T$ cells. By interfering with these immunosuppressive axes, ICls unleash antitumor immune responses, ultimately eliminating cancer cells. ICls have demonstrated promising antitumor efficacy in NSCLC, and mounting evidence supports the use of ICls in treatment-naïve patients with advanced NSCLC. A comprehensive overview of current and emerging ICls for the first-line treatment of NSCLC in China will facilitate a better understanding of NSCLC immunotherapy using ICls and optimize the clinical use of ICls in previously untreated Chinese patients with NSCLC. Herein, we review the efficacy and safety of currently approved and investigational ICls as the first-line treatment of NSCLC in China. We also discuss the challenges limiting more widespread use of ICls and future directions in the first-line treatment of NSCLC using ICls.

Keywords: non-small cell lung cancer (NSCLC), immunotherapy, immune checkpoint inhibitors (ICI), pembrolizumab, China

\section{INTRODUCTION}

Lung cancer is the leading cause of cancer-related death in China, accounting for $23.8 \%$ of all cancer deaths according to the GLOBOCAN 2020 epidemiological data (1). The incidence of lung cancer in China has increased drastically in recent years, posing a significant threat to human health and placing a considerable financial burden on the Chinese healthcare system (2-6). According to the most recent data from the National Cancer Center of China, over 774,000 new cases of lung cancer were diagnosed in 2018 , approximating $18 \%$ of all newly diagnosed cancers (7). In the same year, over 690,000 patients died due to lung cancer (7). In contrast to the increasing incidence of lung cancer in China, the incidence and mortality associated with lung cancer in the US and UK has been decreasing since the 1990s, likely due to the decrease in smoking prevalence in these countries (8). 
Furthermore, the age-standardized mortality rate of lung cancer in China is 1.4 times higher than the corresponding mortality rates in the USA (7).

The vast majority of lung cancers are diagnosed at a locally advanced or metastatic stage, contributing to the low 5-year survival rate (9-11). Lung cancers are broadly classified as nonsmall cell and small cell lung cancer. Non-small cell lung cancer (NSCLC) accounts for $80 \%-85 \%$ of all lung cancer cases (10). NSCLCs are further classified based on the cell type of origin into adenocarcinoma (nearly 66\%), squamous cell carcinoma (nearly $28 \%$ ) and other classified or rare subtypes accounting for approximately $6 \%$ of all NSCLC cases (12).

Cancer immunotherapy is developing rapidly, and multiple immunotherapy options are available for the first-line treatment of NSCLC in China. Immune checkpoint inhibitors (ICIs) are the most promising immunotherapies for NSCLC. Immune checkpoint molecules, such as programmed cell death protein 1 (PD-1)/programmed death-ligand 1 (PD-L1) and cytotoxic Tlymphocyte-associated protein 4 (CTLA-4), deliver negative signals to $\mathrm{T}$ cells, preventing destructive overactivation of the immune system and conferring immunological homeostasis (13). Hence, by blocking immune checkpoint molecules, ICIs unleash antitumor $\mathrm{T}$ cell responses, which, in turn, eliminate cancer cells (14).

Despite the promising antitumor effects of ICIs in patients with NSCLC, there are currently no articles summarizing the efficacy and safety of approved and emerging ICIs for the first-line treatment of NSCLC in China, hindering a better understanding of NSCLC immunotherapy and improvement of immunotherapy outcomes in patients with NSCLC. Therefore, in this article, we comprehensively review current immune checkpoint blockade (ICB) strategies for the first-line treatment of NSCLC in China. We also discuss future directions in the first-line treatment of NSCLC using ICIs.

\section{CURRENT TREATMENT LANDSCAPE FOR ADVANCED NSCLC IN CHINA}

\section{Standard NSCLC Treatment}

The treatment of patients with lung cancer in China is usually based on the pathologic and genetic status of the tumor (15). Surgical resection remains the treatment of choice for patients with early-stage NSCLC; however, postoperative recurrence rates are high, contributing to poor long-term survival outcomes (9, 16). Other conventional therapies commonly used to treat patients with NSCLC include radiotherapy, platinum-based chemotherapy regimens (e.g., pemetrexed plus cisplatin), and the combination of chemotherapy with radiotherapy or antiangiogenic agents (e.g., bevacizumab) (9, 15-17). Nevertheless, the long-term survival outcomes of patients with NSCLC who receive radiotherapy or chemotherapy are unsatisfactory (9).

The clinical implementation of molecular targeted therapies, such as tyrosine kinase inhibitors (TKIs) targeting the epidermal growth factor receptor (EGFR) mutation, anaplastic lymphoma kinase (ALK) rearrangement, and ROS1 rearrangement, etc., has improved the survival outcomes of patients with NSCLC harboring driver mutations $(9,15,18,19)$. However, patients with NSCLC lacking driver mutations do not benefit from targeted therapies $(20,21)$. ICIs, adoptive $\mathrm{T}$ cell therapies, cytokineinduced killer cells, and other emerging immunotherapies are transforming the treatment of NSCLC, especially those lacking driver mutations $(9,22-26)$.

\section{Current NSCLC Immunotherapy Landscape}

The development of immunotherapies, and particularly of antibodies inhibiting CTLA-4 and PD-1/PD-L1 pathways, has revolutionized the treatment of NSCLC and improved the survival outcomes of patients with advanced or metastatic NSCLC in China and worldwide. Despite the fact that immunotherapies have significantly improved the long-term survival outcomes for patients with various tumor types, the development of primary resistance to immunotherapies remains a clinical challenge limiting the clinical benefit of ICIs to only a small proportion of patients (27). Among ICIs, those targeting the PD-1/PD-L1 axis are the most promising, exerting potent antitumor effects by reversing $\mathrm{T}$ cell exhaustion and unleashing antitumor immune responses $(28,29)$. Most immuno-oncology trials in China have focused on the clinical use of anti-PD-1 and anti-PD-L1 antibodies; the efficacy and safety of agents targeting other immunomodulatory molecules, such as TIGIT and LAG3, are also under investigation (30-32).

For patients with advanced, driver oncogene-negative NSCLC, several PD-1/PD-L1 inhibitors have gained regulatory approval in China as first-line treatment, alone or in combination with chemotherapy. China National Medical Products Administration (NMPA)-approved first-line ICIs for advanced NSCLC include pembrolizumab (alone in patients whose tumors express PD-L1 or in combination with pemetrexed/platinum for nonsquamous NSCLC and carboplatin/paclitaxel for squamous NSCLC), atezolizumab (alone in patients whose tumors express PD-L1), camrelizumab (combined with pemetrexed/carboplatin for nonsquamous NSCLC), sintilimab (combined with pemetrexed/ platinum for nonsquamous NSCLC and platinum/gemcitabine for squamous NSCLC), and tislelizumab (combined with pemetrexed/ platinum for nonsquamous NSCLC or with carboplatin/paclitaxel or nab-paclitaxel for squamous NSCLC) (Table 1). In addition to pembrolizumab and atezolizumab, which were developed by multinational corporations $(55,56)$, three locally developed PD1 inhibitors (camrelizumab, tislelizumab, and sintilimab) are also available in China $(31,48,57-59)$.

\section{ICI AS FIRST-LINE THERAPY FOR ADVANCED NSCLC}

\section{Clinical Trials of ICI Monotherapy}

Mounting evidence from randomized controlled trials has confirmed that, compared with platinum-based chemotherapy, ICIs provide better clinical outcomes in patients with advanced 
TABLE 1 | Summary of approval status, indications and supporting clinical trials for immune therapies that are approved for use in patients with NSCLC.

\begin{tabular}{|c|c|c|c|c|}
\hline Drug name & $\begin{array}{l}\text { Trial supporting regu- } \\
\text { latory approval }\end{array}$ & Indication & $\begin{array}{l}\text { NMPA } \\
\text { approval }\end{array}$ & $\begin{array}{l}\text { FDA } \\
\text { approval }\end{array}$ \\
\hline \multirow[t]{3}{*}{$\begin{array}{l}\text { Pembrolizumab } \\
\text { (MSD) }\end{array}$} & KEYNOTE-189 (33) & $\begin{array}{l}\text { In combination with pemetrexed and platinum chemotherapy as a first-line treatment for patients } \\
\text { with metastatic non-squamous NSCLC, with no EGFR or ALK genomic tumor aberrations }\end{array}$ & $\checkmark$ & $\checkmark$ \\
\hline & KEYNOTE-042 (34-36) & $\begin{array}{l}\text { As monotherapy for the first-line treatment of patients with locally advanced or metastatic } \\
\text { NSCLC expressing PD-L1 (Tumor Proportion Score } \geq 1 \% \text { ), with no EGFR or ALK genomic } \\
\text { tumor aberrations }\end{array}$ & $\checkmark$ & $\checkmark$ \\
\hline & $\begin{array}{l}\text { KEYNOTE-407 }(37,38) \\
\text { and KEYNOTE-407 } \\
\text { China extension }(39)\end{array}$ & $\begin{array}{l}\text { In combination with carboplatin and paclitaxel }{ }^{\mathrm{a}} \text { as first-line treatment for patients with metastatic } \\
\text { squamous NSCLC }\end{array}$ & $\checkmark$ & $\checkmark$ \\
\hline \multirow[t]{3}{*}{$\begin{array}{l}\text { Atezolizumab } \\
\text { (Roche) }\end{array}$} & IMpower110 $(40,41)$ & $\begin{array}{l}\text { As monotherapy for the first-line treatment of patients with metastatic NSCLC whose tumors have } \\
\text { high PD-L1 expression (PD-L1 stained } \geq 50 \% \text { of tumor cells or PD-L1 stained tumor-infiltrating } \\
\text { immune cells covering } \geq 10 \% \text { of the tumor area), with no EGFR or ALK genomic tumor aberrations }\end{array}$ & $\checkmark$ & $\checkmark$ \\
\hline & IMpower $150(42,43)$ & $\begin{array}{l}\text { In combination with bevacizumab, paclitaxel, and carboplatin, for the first-line treatment of adult } \\
\text { patients with metastatic non-squamous NSCLC with no EGFR or ALK genomic tumor aberrations }\end{array}$ & $x$ & $\checkmark$ \\
\hline & IMpower $130(44,45)$ & $\begin{array}{l}\text { In combination with albumin-bound paclitaxel and carboplatin for the first-line treatment of adult } \\
\text { patients with metastatic non-squamous NSCLC with no EGFR or ALK genomic tumor aberrations }\end{array}$ & $x$ & $\checkmark$ \\
\hline $\begin{array}{l}\text { Cemiplimab } \\
\text { (Sanofi) }\end{array}$ & EMPOWER Lung 1 (46) & $\begin{array}{l}\text { As monotherapy for the first-line treatment of patients with NSCLC whose tumors have high PD-L1 } \\
\text { expression (Tumor Proportion Score } \geq 50 \% \text { ), with no EGFR, ALK or ROS1 aberrations, and disease } \\
\text { that is locally advanced where patients are not candidates for surgical resection or definitive } \\
\text { chemoradiation, or metastatic }\end{array}$ & $\boldsymbol{x}$ & $\checkmark$ \\
\hline \multirow[t]{2}{*}{$\begin{array}{l}\text { Nivolumab } \\
\text { (BMS) }\end{array}$} & CheckMate-227 (47) & $\begin{array}{l}\text { In combination with ipilimumab as first-line treatment for adult patients with metastatic NSCLC } \\
\text { expressing PD-L1 ( } \geq 1 \%) \text { as determined by an FDA-approved test, with no EGFR or ALK genomic } \\
\text { tumor aberrations }\end{array}$ & $\mathbf{x}$ & $\checkmark$ \\
\hline & CheckMate-9LA (45) & $\begin{array}{l}\text { In combination with ipilimumab and } 2 \text { cycles of platinum-doublet chemotherapy for the first-line } \\
\text { treatment of adult patients with metastatic or recurrent NSCLC with no EGFR or ALK genomic } \\
\text { tumor aberrations }\end{array}$ & $x$ & $\checkmark$ \\
\hline $\begin{array}{l}\text { Camrelizumab } \\
\text { (HengRui) }\end{array}$ & CameL $(48,49)$ & $\begin{array}{l}\text { In combination with pemetrexed and carboplatin as first-line treatment for patients with } \\
\text { unresectable locally advanced or metastatic non-squamous NSCLC, with no EGFR or ALK } \\
\text { genomic tumor aberrations }\end{array}$ & $\mathcal{J}$ & $\boldsymbol{x}$ \\
\hline \multirow[t]{2}{*}{$\begin{array}{l}\text { Tislelizumab } \\
\text { (BeiGene) }\end{array}$} & RATIONALE-307 $(50,51)$ & $\begin{array}{l}\text { In combination with carboplatin and either paclitaxel or albumin-bound paclitaxel, as a first-line } \\
\text { treatment for patients with metastatic squamous NSCLC }\end{array}$ & $\checkmark$ & $\boldsymbol{x}$ \\
\hline & RATIONALE-304 (52) & $\begin{array}{l}\text { In combination with chemotherapy as a first-line treatment for patients with advanced non- } \\
\text { squamous NSCLC }\end{array}$ & $\checkmark$ & $\mathbf{x}$ \\
\hline \multirow[t]{2}{*}{$\begin{array}{l}\text { Sintilimab } \\
\text { (Innovent) }\end{array}$} & ORIENT-11 (53) & $\begin{array}{l}\text { In combination with pemetrexed and platinum chemotherapy as first-line treatment of patients with } \\
\text { advanced or metastatic non-squamous NSCLC, with no EGFR or ALK genomic tumor aberrations }\end{array}$ & $\checkmark$ & $\boldsymbol{x}$ \\
\hline & ORIENT-12 (54) & $\begin{array}{l}\text { In combination with gemcitabine and platinum-based chemotherapy for the first-line treatment of } \\
\text { patients with unresectable advanced or recurrent squamous cell NSCLC }\end{array}$ & $\checkmark$ & $\boldsymbol{x}$ \\
\hline
\end{tabular}

FDA, US food and drug administration; NMPA, China National Medical Products Administration; NSCLC, non-small cell lung cancer; PD-L1, programmed death ligand-1.

${ }^{a}$ The FDA approval included pembrolizumab in combination with carboplatin and paclitaxel or albumin-bound paclitaxel.

NSCLC (Table 2) $(9,67,68)$. Some of the trials were conducted only in China, and some were international multicenter clinical trials that involved Chinese sites (69). The KEYNOTE-001 trial was the first to show that previously untreated patients with advanced or metastatic NSCLC benefited from pembrolizumab monotherapy. In treatment-naive patients, pembrolizumab monotherapy provided a 5-year overall survival (OS) rate of $23.2 \%$. The 5-year OS rate was $29.6 \%$ for treatment-naive patients with PD-L1-high (tumor proportion score [TPS] $\geq$ $50 \%)$ NSCLC and $15.7 \%$ for treatment-naive patients with PDL1-low (TPS 1\%-49\%) NSCLC (70). The subsequent randomized phase III trial KEYNOTE-024 showed that, compared with platinum-based chemotherapy, first-line treatment with pembrolizumab provided better progressionfree survival (PFS), OS, and objective response rate (ORR) in previously untreated patients with metastatic, PD-L1-high (TPS $\geq 50 \%$ ) NSCLC (median PFS, 10.3 vs. 6.0 months; median OS, 26.3 vs. 13.4 months; ORR, $44.8 \%$ vs. $27.8 \%$; updated 5 -year OS rate, $31.9 \%$ vs. $16.3 \%)(60,61)$. The findings of KEYNOTE-024 led to the FDA approval of pembrolizumab as a first-line treatment for selected patients with metastatic EGFR/ALK wild-type NSCLC and with PD-L1 TPS $\geq 50 \%$ (71).

The clinical benefit of first-line pembrolizumab monotherapy in patients with $\mathrm{PD}$-L1-positive and EGFR/ALK wild-type advanced NSCLC was confirmed in the multicenter, randomized, open-label, controlled phase III study KEYNOTE042 (34). In this study, previously untreated patients with advanced NSCLC harboring no EGFR mutation or $A L K$ rearrangement were stratified at randomization based on region of enrollment, performance status, histology, and PD-L1 expression (34). The results demonstrated that, compared with chemotherapy, pembrolizumab monotherapy significantly prolonged OS in patients with locally advanced (stage III) or metastatic NSCLC, with the greatest treatment effect seen in PDL1-high patients (PD-L1 $\geq 50 \%$ : 20.0 vs. 12.2 months; HR, 0.68; 95\% CI, 0.57-0.82; PD-L1 $\geq 20 \%: 18.0$ vs. 13.0 months; HR, 0.75; 95\% CI, $0.64-0.88$; PD-L1 $\geq 1 \%$ : 16.4 vs. 12.1 months; HR, 0.80 ; 
TABLE 2 | Summary of key phase III trials using immune checkpoint inhibitors as first-line monotherapy or combination therapy for NSCLC.

\begin{tabular}{|c|c|c|c|c|c|c|c|c|c|}
\hline Study & $\begin{array}{l}\text { Cohort } \\
\text { size }\end{array}$ & PD-L1 expression & Treatment arms & $\begin{array}{c}\text { NSCLC } \\
\text { histological } \\
\text { type }\end{array}$ & $\begin{array}{l}\text { Median } \\
\text { PFS } \\
\text { (months) }\end{array}$ & $\begin{array}{l}\text { Median } \\
\text { OS } \\
\text { (months) }\end{array}$ & $\begin{array}{l}\text { ORR } \\
(\%)\end{array}$ & OS rate $(\%)^{a}$ & Ref \\
\hline \multicolumn{10}{|c|}{ ICI monotherapy } \\
\hline KEYNOTE-024 & 305 & PD-L1 $\geq 50 \%$ & $\begin{array}{l}\text { Pembrolizumab vs. platinum- } \\
\text { based chemotherapy }\end{array}$ & $N S Q+S Q$ & $\begin{array}{l}10.3 \mathrm{vs} . \\
6.0^{\mathrm{b}}\end{array}$ & $\begin{array}{c}26.3 \text { vs. } \\
13.4\end{array}$ & $\begin{array}{l}44.8 \\
\text { vs. } \\
27.8\end{array}$ & $\begin{array}{l}31.9 \text { vs. } 16.3 \\
\text { (5-year rate) }\end{array}$ & $\begin{array}{l}(60, \\
61)\end{array}$ \\
\hline \multirow[t]{3}{*}{ KEYNOTE-042 } & 1274 & PD-L1 $\geq 1 \%$ & $\begin{array}{l}\text { Pembrolizumab vs. platinum- } \\
\text { based chemotherapy }\end{array}$ & $N S Q+S Q$ & 5.4 vs. 6.5 & $\begin{array}{l}16.4 \text { vs. } \\
12.1^{b}\end{array}$ & $\begin{array}{l}27.0 \\
\text { vs. } \\
27.0\end{array}$ & $\begin{array}{l}25 \text { vs. } 17 \text { (3- } \\
\text { year rate) }\end{array}$ & $\begin{array}{l}(34, \\
35)\end{array}$ \\
\hline & & PD-L1 $\geq 20 \%$ & & & 6.2 vs. 6.6 & $\begin{array}{l}18.0 \mathrm{vs} . \\
13.0^{\mathrm{b}}\end{array}$ & $\begin{array}{c}33 \text { vs. } \\
29\end{array}$ & $\begin{array}{l}28 \text { vs. } 19 \text { (3- } \\
\text { year rate) }\end{array}$ & \\
\hline & & PD-L1 $\geq 50 \%$ & & & 7.1 vs. 6.4 & $\begin{array}{l}20.0 \text { vs. } \\
12.2^{b}\end{array}$ & $\begin{array}{c}39 \text { vs. } \\
32\end{array}$ & $\begin{array}{l}31 \text { vs. } 18 \text { (3- } \\
\text { year rate) }\end{array}$ & \\
\hline \multirow[t]{3}{*}{$\begin{array}{l}\text { KEYNOTE-042 } \\
\text { China extension }\end{array}$} & 262 & PD-L1 $\geq 1 \%$ & $\begin{array}{l}\text { Pembrolizumab vs. platinum- } \\
\text { based chemotherapy }\end{array}$ & $\mathrm{NSQ}+\mathrm{SQ}$ & 6.3 vs. 6.7 & $\begin{array}{l}20.2 \text { vs. } \\
13.5^{\mathrm{b}}\end{array}$ & $\begin{array}{l}31.3 \\
\text { vs. } \\
24.6\end{array}$ & 43.8 vs. & $(36)$ \\
\hline & & PD-L1 $\geq 20 \%$ & & & 6.2 vs. 7.2 & $\begin{array}{l}21.9 \text { vs. } \\
13.5^{\mathrm{b}}\end{array}$ & $\begin{array}{l}33.7 \\
\text { vs. } \\
24.3\end{array}$ & $\begin{array}{l}28.2 \text { (2-year } \\
\text { rate) }\end{array}$ & \\
\hline & & PD-L1 $\geq 50 \%$ & & & 8.3 vs. 6.5 & $\begin{array}{l}24.5 \text { vs. } \\
13.8^{b}\end{array}$ & $\begin{array}{l}40.3 \\
\text { vs. } \\
24.3\end{array}$ & $\begin{array}{c}46.5 \text { vs. } \\
28.7 \text { (2-year } \\
\text { rate) } \\
50.0 \text { vs. } \\
29.7 \text { (2-year } \\
\text { rate) }\end{array}$ & \\
\hline IMpower110 & 554 & $\begin{array}{l}\text { TC 1/2/3/and IC 1/2/3 } \\
\text { (analysis in TC 3/IC 3) }\end{array}$ & Atezolizumab vs. chemotherapy & $N S Q+S Q$ & 8.1 vs. 5.0 & $\begin{array}{l}20.2 \text { vs. } \\
14.7^{b}\end{array}$ & $\begin{array}{l}38.3 \\
\text { vs. } \\
28.6\end{array}$ & & $\begin{array}{l}(40, \\
41)\end{array}$ \\
\hline $\begin{array}{l}\text { EMPOWER } \\
\text { Lung } 1\end{array}$ & 563 & PD-L1 $\geq 50 \%$ & Cemiplimab vs. chemotherapy & $\mathrm{NSQ}+\mathrm{SQ}$ & 8.2 vs. $5.7^{b}$ & $\begin{array}{l}\text { NR vs. } \\
14.2^{b}\end{array}$ & $\begin{array}{l}39 \text { vs. } \\
20\end{array}$ & & $(46)$ \\
\hline CheckMate 026 & 423 & $\begin{array}{l}\text { PD-L1 } \geq 1 \% \text { (primary } \\
\text { endpoint assessed in PD-L1 } \\
\geq 5 \% \text { ) }\end{array}$ & Nivolumab vs. chemotherapy & $N S Q+S Q$ & 4.2 vs. $5.9^{b}$ & $\begin{array}{c}14.4 \text { vs. } \\
13.2\end{array}$ & $\begin{array}{l}26.0 \\
\text { vs. } \\
33.0\end{array}$ & & $(62)$ \\
\hline \multicolumn{10}{|c|}{ ICI plus chemotherapy } \\
\hline KEYNOTE-189 & 616 & PD-L1 unselected & Pembrolizumab/PC vs. PC & NSQ & 9.0 vs. $4.9^{b}$ & $\begin{array}{l}22.0 \text { vs. } \\
10.7^{b}\end{array}$ & $\begin{array}{l}48.0 \\
\text { vs. } \\
19.4\end{array}$ & $\begin{array}{l}31.3 \text { vs. } 17.4 \\
\text { (3-year rate) }\end{array}$ & (33) \\
\hline IMpower130 & 723 & PD-L1 unselected & $\begin{array}{l}\text { Atezolizumab/chemotherapy vs. } \\
\text { chemotherapy }\end{array}$ & NSQ & 7.0 vs. $5.5^{b}$ & $\begin{array}{l}18.6 \mathrm{vs} . \\
13.9^{\mathrm{b}}\end{array}$ & $\begin{array}{c}49.2 \\
\text { vs. } \\
31.9\end{array}$ & $\begin{array}{l}39.6 \text { vs. } 30.0 \\
\text { (2-year rate) }\end{array}$ & $\begin{array}{l}(44, \\
45)\end{array}$ \\
\hline CameL & 412 & PD-L1 unselected & $\begin{array}{l}\text { Camrelizumab/ chemotherapy } \\
\text { vs. chemotherapy }\end{array}$ & NSQ & $\begin{array}{l}11.3 \mathrm{vs} . \\
8.3^{\mathrm{b}}\end{array}$ & $\begin{array}{c}27.9 \text { vs. } \\
20.5\end{array}$ & $\begin{array}{l}60.5 \\
\text { vs. } \\
38.6\end{array}$ & & $\begin{array}{l}(48, \\
49)\end{array}$ \\
\hline ORIENT-11 & 397 & PD-L1 unselected & $\begin{array}{l}\text { Sintilimab/ chemotherapy vs. } \\
\text { chemotherapy }\end{array}$ & NSQ & 8.9 vs. $5.0^{b}$ & $\begin{array}{l}\text { Not } \\
\text { reported }\end{array}$ & $\begin{array}{l}51.9 \\
\text { vs. } \\
29.8\end{array}$ & & $(53)$ \\
\hline ORIENT-12 & 357 & PD-L1 unselected & $\begin{array}{l}\text { Sintilimab/chemotherapy vs. } \\
\text { chemotherapy }\end{array}$ & $\mathrm{SQ}$ & 5.5 vs. $4.9^{b}$ & $\begin{array}{l}\text { Not } \\
\text { reached }\end{array}$ & $\begin{array}{c}44.7 \\
\text { vs. } \\
35.4\end{array}$ & & $(54)$ \\
\hline $\begin{array}{l}\text { RATIONALE } \\
304\end{array}$ & 332 & PD-L1 unselected & $\begin{array}{l}\text { Tislelizumab/chemotherapy vs. } \\
\text { chemotherapy }\end{array}$ & NSQ & 9.7 vs. $7.6^{b}$ & $\begin{array}{l}\text { Not } \\
\text { reached }\end{array}$ & $\begin{array}{l}57.4 \\
\text { vs. } \\
36.9\end{array}$ & & $(52)$ \\
\hline KEYNOTE-407 & 559 & PD-L1 unselected & $\begin{array}{l}\text { Pembrolizumab/chemotherapy } \\
\text { vs. carboplatin/ nab-paclitaxel }\end{array}$ & $\mathrm{SQ}$ & 8.0 vs. $5.1^{b}$ & $\begin{array}{l}17.1 \mathrm{vs} . \\
11.6^{\mathrm{b}}\end{array}$ & $\begin{array}{l}62.6 \\
\text { vs. } \\
38.4\end{array}$ & $\begin{array}{c}29.7 \text { vs. } 18.2 \\
\text { (3-year rate) }\end{array}$ & $\begin{array}{l}(37, \\
38)\end{array}$ \\
\hline $\begin{array}{l}\text { KEYNOTE-407 } \\
\text { China extension }\end{array}$ & 125 & PD-L1 unselected & $\begin{array}{l}\text { pembrolizumab/chemotherapy } \\
\text { vs. carboplatin/ (nab-) paclitaxel }\end{array}$ & $\mathrm{SQ}$ & $8.3^{\mathrm{b}}$ vs. 4.2 & $\begin{array}{l}17.3 \mathrm{vs} . \\
12.6^{\mathrm{b}}\end{array}$ & $\begin{array}{c}78.5 \\
\text { vs. } \\
41.7\end{array}$ & & $(63)$ \\
\hline CameL-sq & 390 & PD-L1 unselected & $\begin{array}{l}\text { Camrelizumab/ chemotherapy } \\
\text { vs. chemotherapy }\end{array}$ & $\mathrm{SQ}$ & 8.5 vs. $4.9^{b}$ & $\begin{array}{l}\text { NR vs. } \\
14.5\end{array}$ & $\begin{array}{l}64.8 \\
\text { vs. } \\
36.7\end{array}$ & & $(64)$ \\
\hline $\begin{array}{l}\text { RATIONALE } \\
307\end{array}$ & 360 & PD-L1 unselected & $\begin{array}{l}\text { Tislelizumab/PC or nab-PC vs. } \\
\text { PC }\end{array}$ & $\mathrm{SQ}$ & $\begin{array}{c}7.6,7.6 \mathrm{vs} . \\
5.5^{\mathrm{b}}\end{array}$ & $\begin{array}{l}\text { Not } \\
\text { reported }\end{array}$ & $\begin{array}{l}73,75 \\
\text { vs. } 50\end{array}$ & & $\begin{array}{l}(50, \\
51)\end{array}$ \\
\hline
\end{tabular}


TABLE 2 | Continued

\begin{tabular}{|c|c|c|c|c|c|c|c|c|c|}
\hline Study & $\begin{array}{l}\text { Cohort } \\
\text { size }\end{array}$ & PD-L1 expression & Treatment arms & $\begin{array}{c}\text { NSCLC } \\
\text { histological } \\
\text { type }\end{array}$ & $\begin{array}{l}\text { Median } \\
\text { PFS } \\
\text { (months) }\end{array}$ & $\begin{array}{l}\text { Median } \\
\text { OS } \\
\text { (months) }\end{array}$ & $\begin{array}{l}\text { ORR } \\
(\%)\end{array}$ & OS rate $(\%)^{a}$ & Ref \\
\hline $\begin{array}{l}\text { GEMSTONE- } \\
302\end{array}$ & 479 & PD-L1 unselected & $\begin{array}{l}\text { Sugemalimab/chemotherapy vs. } \\
\text { chemotherapy }\end{array}$ & $\mathrm{NSQ}+\mathrm{SQ}$ & 7.8 vs. $4.9^{b}$ & $\begin{array}{l}\text { Not } \\
\text { reported }\end{array}$ & $\begin{array}{l}61.4 \\
\text { vs. } \\
39.2\end{array}$ & & (65) \\
\hline \multicolumn{10}{|c|}{$\mathrm{ICI}$ plus chemotherapy and antiangiogenic therapy } \\
\hline IMpower150 & 1202 & $\begin{array}{l}\text { Analysis in PD-L1 unselected, } \\
\text { EGFR/ALK } \\
\text { WT (study included any } \\
\text { EGFR/ALK status) }\end{array}$ & $\begin{array}{l}\text { Chemotherapy plus } \\
\text { bevacizumab } \pm \text { atezolizumab }\end{array}$ & $N S Q$ & 8.3 vs. $6.8^{b}$ & $\begin{array}{l}19.5 \mathrm{vs} . \\
14.7^{\mathrm{b}}\end{array}$ & $\begin{array}{c}63.5 \\
\text { vs. } \\
48.0\end{array}$ & $\begin{array}{l}43.4 \text { vs. } 33.7 \\
\text { (2-year rate) }\end{array}$ & $\begin{array}{l}(42, \\
43)\end{array}$ \\
\hline \multicolumn{10}{|c|}{ Dual ICI } \\
\hline KEYNOTE-598 & 568 & PD-L1 $\geq 50 \%$ & Pembrolizumab \pm ipilimumab & $\mathrm{NSQ}+\mathrm{SQ}$ & 8.2 vs. $8.4^{b}$ & $\begin{array}{l}21.4 \text { vs. } \\
21.9^{b}\end{array}$ & $\begin{array}{c}45.4 \\
\text { vs. } \\
45.4\end{array}$ & & (66) \\
\hline $\begin{array}{l}\text { CheckMate } 227 \\
\text { part 1a }\end{array}$ & 1189 & PD-L1 $\geq 1 \%$ & $\begin{array}{l}\text { Ipilimumab/ nivolumab vs. } \\
\text { chemotherapy }\end{array}$ & $\mathrm{NSQ}+\mathrm{SQ}$ & 5.1 vs. $5.6^{b}$ & $\begin{array}{l}17.1 \mathrm{vs} . \\
14.9^{\mathrm{b}}\end{array}$ & $\begin{array}{c}35.9 \\
\text { vs. } \\
30.0\end{array}$ & $\begin{array}{l}40.0 \text { vs. } 32.8 \\
\text { (2-year rate) }\end{array}$ & $(47)$ \\
\hline \multicolumn{10}{|c|}{ Dual ICI plus chemotherapy } \\
\hline CheckMate 9LA & 719 & PD-L1 unselected & $\begin{array}{l}\text { Ipilimumab/ nivolumab/ } \\
\text { chemotherapy vs. chemotherapy }\end{array}$ & $N S Q+S Q$ & 6.8 vs. 5.0 & $\begin{array}{l}15.6 \mathrm{vs} . \\
10.9^{b}\end{array}$ & $\begin{array}{l}37.7 \\
\text { vs. } \\
25.1\end{array}$ & & $(45)$ \\
\hline
\end{tabular}

IC, tumor-infiltrating immune cells covering \% of the tumor area; ICI, immune checkpoint inhibitor; NSQ, nonsquamous cell carcinoma; OS, overall survival; PFS, progression-free survival; $P C$, carboplatin/pemetrexed; ORR, objective response rate; SQ, squamous cell carcinoma; TC, expression of PD-L1 on tumor cells.

anly survival rates $\geq 2$ years are shown.

${ }^{b}$ Primary endpoint.

95\% CI, 0.71-0.90) (34, 35). Based on these findings, FDA approval of pembrolizumab monotherapy as a first-line treatment was extended to patients with locally advanced (stage III) or metastatic, EGFR/ALK wild-type NSCLC and with PD-L1 TPS $\geq 1 \%$ as determined by an FDA-approved test (72).

In an extension of the KEYNOTE-042 study in a Chinese cohort, pembrolizumab monotherapy significantly improved OS compared with chemotherapy alone in patients with PD-L1positive NSCLC with a PD-L1 TPS $\geq 50 \%$ (median OS, 24.5 vs 13.8 months; HR, 0.63 ; 95\% CI, 0.43-0.94), TPS $\geq 20 \%$ (median OS, 21.9 vs 13.5 months; HR, 0.66; 95\% CI, 0.47-0.92), and TPS $\geq 1 \%$ (median OS, 20.2 vs 13.5 months; HR, 0.67; 95\% CI, 0.50-0.89) (36). The results of the KEYNOTE-042 China extension study were crucial for the approval of pembrolizumab monotherapy as a first-line treatment of advanced PD-L1-positive NSCLC in China $(36,56)$.

Atezolizumab is an anti-PD-L1 monoclonal antibody recently approved by the FDA and the NMPA for the first-line treatment of patients with metastatic, $\mathrm{PD}$-L1 high expression nonsquamous or squamous NSCLC harboring no EGFR mutation or ALK rearrangement. This approval was based on the findings of IMpower110 (NCT02409342), an international, randomized, open-label trial comparing the efficacy of atezolizumab to that of platinum-based chemotherapy in chemotherapy-naïve patients with stage IV NSCLC expressing PD-L1 on $\geq 1 \%$ of tumor cells ( $\mathrm{TC} \geq 1 \%$ ) or tumor-infiltrating immune cells (IC $\geq$ $1 \%$ ). In patients with high PD-L1 expression (TC $\geq 50 \%$ or IC $\geq$ $10 \%$ ), atezolizumab provided longer OS (median, 20.2 vs. 13.1 months; stratified HR, 0.59; 95\% CI, 0.40-0.89) and PFS (median, 8.1 vs. 5.0 months; stratified HR, 0.63; 95\% CI, 0.45-
0.88) than chemotherapy $(40,73,74)$. An updated analysis of IMpower110 found no difference in OS for atezolizumab versus chemotherapy for patients with high or intermediate $(\geq 5 \%$ TC or IC) PD-L1 expression ( $\mathrm{n}=328$; median, 19.9 vs 16.1 months; $\mathrm{HR}, 0.87 ; 95 \% \mathrm{CI}, 0.66-1.14) ; P=0.3091$ ) and endpoints were therefore not formally tested in patients with any PD-L1 expression (41). However, an exploratory analysis showed that the OS benefit observed for atezolizumab versus chemotherapy in patients with high PD-L1 expression (TC $\geq 50 \%$ or IC $\geq 10 \%$ ) was maintained after 17 months' additional follow-up (median, 20.2 vs 14.7 months; HR, 0.76; 95\% CI, 0.54-1.09) (41).

Cemiplimab is an FDA-approved monoclonal antibody targeting PD-1 for the first-line treatment of patients with locally advanced or metastatic, PD-L1-high nonsquamous and squamous NSCLC harboring no EGFR/ALK/ROS1 alterations. The global, multicenter, open-label phase III study EMPOWERLung 1 investigated the efficacy and safety of cemiplimab in treatment-naïve patients with advanced squamous or nonsquamous NSCLC expressing high PD-L1 levels (TPS $\geq 50 \%$ ). Preliminary data showed that compared with platinum-doublet chemotherapy, cemiplimab provided superior OS (median, NR vs. 14.2 months; HR, 0.57; 95\% CI, 0.42-0.77) and PFS (median, 8.2 vs. 5.7 months; HR, 0.54 ; 95\% CI, 0.43-0.68) in patients with NSCLC expressing high PD-L1 levels. The toxicity profile of cemiplimab was also superior to that of platinum-doublet chemotherapy (46).

No benefit has been observed with nivolumab monotherapy in this setting. The open-label, randomized, phase III clinical study CheckMate 026 compared first-line nivolumab with chemotherapy in 423 previously untreated patients with PDL1-positive (PD-L1 $\geq 5 \%$ ) NSCLC. The median PFS (primary 
endpoint) in nivolumab-treated patients was 4.2 months, not significantly different from the median PFS of 5.9 months in patients treated with chemotherapy (HR, 1.15; 95\% CI, 0.91$1.45 ; P=0.25$ ). The OS (secondary endpoint) was similar in the nivolumab and chemotherapy groups (median, 14.4 vs. 13.2 months; HR, 1.02; 95\% CI, 0.80-1.30) (62).

\section{Clinical Trials of ICI Combination Therapy}

Data suggests that PD-L1 is upregulated in tumors during chemotherapy $(75,76)$. Additionally, chemotherapy enhances the presentation of tumor antigens and reduces the number of different Treg subsets (77-79). Hence, the efficacy of first-line PD-1/PD-L1 inhibitors combined with chemotherapy has been evaluated in patients with NSCLC. In the phase II KEYNOTE021 trial, data from Cohort $G$ showed that first-line pembrolizumab combined with chemotherapy provided a higher ORR (58\% vs. 33\%) and longer PFS (median, 24.5 vs. 9.9 months), and a long-term follow up (median 49.4 months) revealed a longer OS (median, 34.5 vs. 21.1 months; HR, 0.71; 95\% CI, 0.45-1.12), versus chemotherapy alone in patients with advanced EGFR/ALK wild-type, nonsquamous NSCLC (80-82). A subsequent phase III study (KEYNOTE-189) of patients with metastatic EGFR/ALK wild-type nonsquamous NSCLC has shown that, compared with pemetrexed and platinum-based chemotherapy alone, first-line pembrolizumab plus chemotherapy conferred better OS (median, 22.0 vs. 10.7 months; HR, 0.56; 95\% CI, 0.45-0.70), 3-year OS rate (31.3 vs. $17.4 \%$ ) and PFS (median, 9.0 vs. 4.9 months; HR, 0.48; $95 \% \mathrm{CI}$, $0.40-0.58$ ); ORR ( $48.0 \%$ vs. $19.4 \%$ ) was also extended by $28.6 \%$ in patients who received combination therapy (33). Similarly, in the phase III KEYNOTE-407 trial, the combination of pembrolizumab with chemotherapy (carboplatin and paclitaxel or nab-paclitaxel) provided longer OS (median, 17.1 vs. 11.6 months; HR, 0.71; 95\% CI, 0.58-0.88), 3-year OS rate (29.7 vs. $18.2 \%$ ) and PFS (median, 8.0 vs. 5.1 months; HR, 0.57; 95\% CI, 0.47-0.69) compared with chemotherapy alone in patients with metastatic squamous NSCLC (37). In the KEYNOTE-407 China extension study, the efficacy of pembrolizumab plus chemotherapy (carboplatin and paclitaxel) in PD-L1unselected patients with metastatic squamous NSCLC was compared to that of chemotherapy alone. Compared with chemotherapy alone, the combination therapy provided superior PFS (median, 8.3 vs. 4.2 months; HR; 0.32 95\% CI, 0.21-0.49), OS (median, 17.3 vs. 12.6 months; HR; $0.4495 \% \mathrm{CI}$, $0.24-0.81$ ), and ORR (78.5\% vs. $41.7 \%)$ (63). Patients in the KEYNOTE-189 and KEYNOTE-407 studies were not selected based on PD-L1 expression levels (37). Based on the findings of these studies, the NMPA has approved pembrolizumab as a firstline treatment in combination with pemetrexed and platinum chemotherapy for metastatic nonsquamous NSCLC (EGFR/ALK wild-type) and in combination with carboplatin and paclitaxel for metastatic squamous NSCLC (83).

Other ICIs have also been investigated as combination therapy for the first-line treatment of advanced NSCLC. Camrelizumab was a newly developed domestic anti-PD-1 monoclonal antibody approved by the NMPA for first-line use in patients with nonsquamous NSCLC in China. CameL (NCT03134872) was a randomized, open-label, phase III trial evaluating the efficacy of camrelizumab combined with carboplatin and pemetrexed in Chinese treatment-naïve patients with advanced nonsquamous NSCLC without EGFR and ALK alterations. Compared with chemotherapy alone, combination therapy significantly prolonged PFS (median, 11.3 vs. 8.3 months; HR; $0.6095 \% \mathrm{CI}, 0.45-0.79$ ). Camrelizumab combined with chemotherapy also prolonged OS (median, 27.9 vs. 20.5 months; HR; $0.7395 \% \mathrm{CI}, 0.55-0.96$ ), which was the secondary endpoint of the study (48). The efficacy of first-line camrelizumab combined with carboplatin and paclitaxel was also investigated in patients with advanced squamous NSCLC in the randomized, double-blind, phase III clinical study CameL-sq (NCT03668496). In this cohort, the combination of camrelizumab with chemotherapy significantly prolonged PFS, which was the primary endpoint of the study. Specifically, the median PFS was 8.5 months in patients treated with camrelizumab plus chemotherapy and 4.9 months in patients treated with placebo plus chemotherapy (HR, 0.37; 95\% CI, 0.290.47). OS was not reached in the camrelizumab plus chemotherapy arm and was 14.5 months in the placebo plus chemotherapy arm (64).

The multicenter randomized trial IMpower130 (NCT02367781) investigated the efficacy of atezolizumab combined with standard chemotherapy in treatment-naïve patients with metastatic nonsquamous NSCLC. The combination of atezolizumab with nab-paclitaxel and carboplatin provided longer OS (median, 18.6 vs. 13.9 months; HR; 0.79 95\% CI, 0.64-0.98) and PFS (median, 7.0 vs. 5.5 months; HR; $0.6495 \% \mathrm{CI}, 0.54-0.77)$ than chemotherapy alone in patients without EGFR and ALK alterations (44). The multicenter, randomized, phase III trial IMpower 150 (NCT02366143) evaluated the antitumor effects of first-line atezolizumab combined with chemotherapy (carboplatin plus paclitaxel) and antiangiogenic therapy (bevacizumab) in patients with metastatic nonsquamous NSCLC. Compared with chemotherapy plus bevacizumab, the combination of atezolizumab with chemotherapy and bevacizumab provided longer OS (median, 19.5 vs. 14.7 months; HR; 0.80 95\% CI 0.670.95 ) and PFS (median, 8.3 vs. 6.8 months; HR; 0.62 95\% CI $0.52-$ 0.74 ) in patients with $E G F R / A L K$ wild-type NSCLC $(42,43)$.

The efficacy of first-line dual immunotherapy alone or in combination with chemotherapy has also been evaluated. In part 1a of the phase III CheckMate 227 trial, previously untreated patients with advanced NSCLC (EGFR/ALK wild-type) and PD$\mathrm{L} 1 \geq 1 \%$ were randomized ( $1: 1: 1)$ to nivolumab plus ipilimumab, nivolumab alone or chemotherapy alone (47). In part 1b, patients with $\mathrm{PD}-\mathrm{L} 1<1 \%$ were randomly assigned to nivolumab plus ipilimumab, nivolumab plus chemotherapy, or chemotherapy alone. The results from CheckMate 227 part 1a showed that combination immunotherapy with nivolumab plus ipilimumab led to a better OS and moderately higher PFS and ORR than chemotherapy alone (median OS: 17.1 vs. 14.9 months; HR, 0.79; 97.72\% CI, 0.65-0.96; median PFS: 5.1 vs. 5.6 months; HR, 0.82; 95\% CI, 0.69-0.97; ORR: $35.9 \%$ vs. $30.0 \%$ ); in patients with a PDL1 expression level $\geq 1 \%$. In the global phase III study CheckMate 
9LA, treatment-naïve patients with advanced NSCLC were randomly assigned to receive nivolumab plus ipilimumab combined with two cycles of chemotherapy or chemotherapy alone. Compared with chemotherapy alone, the combination of nivolumab plus ipilimumab with two cycles of chemotherapy significantly improved the OS of previously untreated patients with advanced NSCLC [median OS: 15.6 vs. 10.9 months; HR, 0.66; 95\% CI, 0.55-0.80 (84)]. However, these studies did not include Chinese patients.

\section{Ongoing Clinical Trials}

Currently, various domestic and imported ICIs are under clinical investigation in China for use in the first-line treatment of advanced NSCLC combined with chemotherapy or anti-VEGF antibody or as dual ICI therapy. The results of key phase III trials are summarized in Table 1. Trials of sintilimab, tislelizumab and sugemalimab (e.g., ORIENT-11, ORIENT-12, RATIONALE 304, RATIONALE 307, GEMSTONE-302) have already reported their interim analysis of the primary endpoints and confirmation of OS benefit needs a longer follow-up. Other studies (e.g., IMpower151, LEAP 006, LEAP 007) are still under investigation.

Sintilimab is a humanized anti-PD-1 monoclonal antibody approved by the NMPA for the first-line treatment of patients with nonsquamous and squamous $\operatorname{NSCLC}(85,86)$. ORIENT-11 (NCT03607539) was a randomized, double-blind, phase III study investigating the use of sintilimab combined with pemetrexed and platinum chemotherapy in patients with locally advanced or metastatic nonsquamous NSCLC; patients were stratified by PDL1 expression (TPS $\geq 1 \%$ or $<1 \%$ ). Analysis of the primary endpoint (PFS) showed that, compared with chemotherapy alone, sintilimab plus chemotherapy prolonged PFS (median, 8.9 vs. 5.0 months; HR; 0.482 95\% CI, 0.362-0.643) (53). ORIENT-12 (NCT03629925) was a randomized, double-blind, phase III study assessing the efficacy and safety of sintilimab combined with gemcitabine and platinum-based chemotherapy in previously untreated patients with advanced or recurrent squamous NSCLC. An updated analysis after a 12.9-month median follow-up revealed a median PFS of 5.5 months in the combination treatment group vs. 4.9 months in the chemotherapy alone group (HR, 0.536; 95\% CI, 0.422-0.681). Toxicities were similar in the two treatment groups (54).

Tislelizumab is a humanized anti-PD-1 monoclonal antibody approved by the NMPA for use in patients with nonsquamous or squamous NSCLC. The randomized, open-label, phase III RATIONALE 304 (NCT03663205) trial assessed the efficacy and safety of tislelizumab plus chemotherapy (pemetrexed and carboplatin or cisplatin) versus chemotherapy alone in treatment-naïve patients with advanced nonsquamous NSCLC (52). The preliminary results of this study revealed a significantly longer PFS with tislelizumab versus chemotherapy (median, 9.7 vs. 7.6 months; HR, 0.645; 95\% CI, 0.462-0.902). Furthermore, the ongoing RATIONALE 307 (NCT03594747) study is a randomized, open-label, phase III trial investigating the firstline use of tislelizumab combined with chemotherapy (carboplatin and paclitaxel or nab-paclitaxel) in patients with advanced squamous NSCLC. Preliminary data from
RATIONALE 307 showed that, compared with chemotherapy alone, the combination of tislelizumab plus chemotherapy significantly improved median PFS and ORR in patients with squamous NSCLC $(50,67)$.

Sugemalimab (CS1001) is an investigational monoclonal antibody targeting human PD-L1, and GEMSTONE-302 is a randomized, double-blind, phase III study evaluating the efficacy and safety of sugemalimab plus platinum-based chemotherapy in previously untreated patients with advanced squamous or nonsquamous NSCLC. Preliminary data suggest that first-line sugemalimab combined with chemotherapy may prolong patient survival (ITT: median PFS 7.82 vs. 4.90 months [HR, 0.50 (95\% CI, 0.39-0.64)]; nonsquamous: median PFS 8.57 vs. 5.16 months [HR, 0.66]; squamous: median PFS 7.16 vs. 4.70 months, [HR, $0.33]$ ). ORRs were $61.4 \%$ (56.2\% for nonsquamous, $69.0 \%$ for squamous) in the sugemalimab plus chemotherapy group and $39.2 \%$ (34.7\% for nonsquamous, $46.0 \%$ for squamous) in the chemotherapy alone group (65).

\section{PD-L1 Expression Level as a Predictor of Response to First-Line Immunotherapy of NSCLC}

Mounting clinical evidence suggests that in NSCLC and other immunogenic malignancies, PD-L1 expression levels in tumor cells are strongly associated with response to $\mathrm{PD}-1 / \mathrm{PD}-\mathrm{L} 1$ inhibitors. Currently, PD-L1 expression in tumor cells is the most important predictive biomarker of response to ICIs. In NSCLC, high PD-L1 expression levels in tumor cells have been associated with favorable response to immunotherapy and prolonged survival after first-line therapy with ICIs (87). Given the use of pembrolizumab as first-line treatment for certain patients with NSCLC, PD-L1 expression testing and EGFR/ $A L K$ status testing are recommended at the first diagnosis of patients with advanced NSCLC in China, according to the 2020 Chinese Society of Clinical Oncology (CSCO) guidelines $(55,56)$.

PD-L1 IHC 22C3 pharmDx, a PD-L1 antibody reagent, was approved by the NMPA as a qualitative immunohistochemical assay to assess PD-L1 expression in formalin-fixed, paraffinembedded NSCLC biopsy/surgical pathology specimens using a monoclonal mouse anti-PD-L1 antibody (clone 22C3, code M3653, Dako) on May 8, 2020 (88). In China, PD-L1 detection using PD-L1 IHC 22C3 pharmDx is currently used to identify patients with NSCLC suitable for treatment with pembrolizumab (55). PD-L1 IHC 22C3 pharmDx was also licensed in the US and Europe as a companion diagnostic test for pembrolizumab treatment of NSCLC (88). The kit is used to assess the TPS for PD-L1 to determine the proportion of viable cancer cells showing partial or complete PD-L1 membrane staining $(55,88)$. Typically, specimens with TPS $<1 \%$ are considered as PD-L1-negative, whereas samples with TPS $\geq 1 \%$ are considered as PD-L1-positive; TPS 1\%-49\% indicates a low PD-L1 expression and TPS $\geq 50 \%$ indicates a high PD-L1 expression $(55,88)$. Similarly, VENTANA PD-L1 (SP142) Assay has been approved by the FDA as a companion diagnostic test to identify patients with NSCLC who are most likely to benefit from atezolizumab. The test can be used to determine PD-L1 expression based on both tumor cell staining 
(TC score) and tumor-infiltrating immune cell staining (IC score) $(58,89)$.

\section{ADVERSE REACTIONS RELATED TO ICIS}

Immune checkpoints are key molecules in maintaining immune homeostasis and preventing tissue damage due to excessive or prolonged immune system activation. Thus, ICIs can induce various immune-related adverse events (IRAEs) (68). The most commonly affected systems in patients experiencing IRAEs are the gastrointestinal, dermatological, and endocrine systems (68). The most common side effects of ICIs are rash and mucosal irritation, occurring in nearly $50 \%$ of patients (27). Diarrhea is also common among patients treated with ICIs, especially among those receiving CTLA-4 inhibitors. However, most adverse events are mild or moderate, with grade 3 or 4 diarrhea occurring in less than $10 \%$ of patients receiving ICIs (27). Autoimmune hepatotoxicity, indicated by an increase in aspartate aminotransferase levels, is a severe yet less common side effect occurring in less than $10 \%$ of patients receiving $\mathrm{PD}-1 /$ PD-L1 inhibitors (27). Pulmonary, neurologic, hematologic, and cardiac adverse effects have also been reported. In a real-world retrospective analysis of Chinese patients with NSCLC who received ICIs, Chen et al. (90) reported a $46.4 \%$ incidence of IRAEs, most of which were grade 2 ; grade 3 or 4 IRAEs occurred in $9.4 \%$ of patients. The study also revealed that treatment interruption due to severe IRAEs (myocarditis, pneumonia, and grade 4 bullous lung disease) was relatively rare (90).

\section{CHALLENGES AND FUTURE DIRECTIONS}

ICIs have led to remarkable improvements in survival outcomes in patients with advanced NSCLC compared with conventional chemotherapy. The long-term survival benefit of ICIs results in characteristic "long tail" survival curves. Notwithstanding the promising safety and efficacy of pembrolizumab and other ICIs for the first-line treatment of NSCLC, in general, a proportion of patients will not achieve a response to ICI therapy. Future clinical studies are therefore required to identify strategies to expand the proportion of patients who benefit from treatment with ICIs through identification of patients likely to respond to ICI therapy, developing strategies to overcome immunotherapy resistance, exploring the potential benefit of ICIs for patients with EGFR-mutant NSCLC and better understanding the safety profile of ICI therapy $(91,92)$.

Further research is required to identify and validate factors predicting response to pembrolizumab and other ICIs, and this would facilitate the identification of patients most likely to benefit from ICB alone or in combination with chemotherapy (93). Given that resistance to ICIs is common, approaches to accurately predict ICI response will spare non-responders from the unnecessary adverse effects of immunotherapy (55). Factors including gut microbiota (28) and tumor mutation burden (TMB) (94) have been associated with response to ICI in preliminary studies but require further investigation and validation in large cohort studies. In addition, in China, there are many challenges for PD-L1 testing, and the clinical application of PD-L1 testing is still at an early stage (55, 56, 83). The establishment of standardized guidelines on PD-L1 testing will enhance the clinical significance of PD-L1 testing as a means to predict response to PD-1/PD-L1 inhibitors (55). Given the high intertumoral and intratumoral heterogeneity in PD-L1 expression, future studies are also warranted to identify other robust biomarkers (e.g., serum biomarkers, neutrophil-tolymphocyte ratio) for predicting response to ICIs (83, 95-97). These biomarkers should comprehensively capture the immunological status of the tumor based on multiple components of the tumor microenvironment rather than the expression of a single checkpoint molecule $(95,96,98)$.

Tumor immune escape and development of resistance to immunotherapies remain significant challenges limiting the clinical benefit of ICIs (91). Therefore, the development of strategies to target mechanisms driving immune tolerance and immunotherapy resistance will maximize the clinical benefit of pembrolizumab and other ICIs, as well as facilitate long-lasting responses. Promising actionable targets driving immune tolerance are regulatory T cells (Tregs), M2 phenotype tumorassociated macrophages (TAMs), and myeloid-derived suppressor cells (MDSCs) (99). Immunomodulatory pathways include IFN $\gamma$, mitogen-activated protein kinase (MAPK), and $\mathrm{WNT} / \beta$-catenin pathways. The potential clinical benefit of treatment regimens combining ICIs, chemotherapy, radiotherapy, targeted therapies, and antiangiogenic therapies should be further explored as promising ways to combat resistance of NSCLC to ICIs (100).

The potential use of ICIs to treat patients with EGFR-mutant NSCLC merits further investigation $(101,102)$. The relationship between PD-L1/PD-1 expression levels and EGFR mutation status, as well as the interaction between the PD-1/PD-L1 and EGFR pathways, are poorly understood (56, 103-106). Notably, a large-scale, multicenter, real-world study in China identified a significant association between PD-L1 expression levels and EGFR mutation and $A L K$ rearrangement (107). Future Chinese studies are critical to addressing this issue given the higher EGFR mutation rates in Chinese patients with NSCLC compared with their Western counterparts (approximately 28\% in unselected Chinese patients with NSCLC vs. $17 \%$ in Western populations) $(28,108,109)$.

As most clinical trials investigating the use of ICIs are still ongoing, more clinical data from large-cohort, long-term studies are required to elucidate the adverse effects associated with ICB, especially in elderly ( $\geq 65$ years old) and immunocompromised patients. In China, the management of IRAEs is based on Management of Immunotherapy-Related Toxicities guidelines, version 1.2019, although NCCN Management of Immunotherapy-Related Toxicities guidelines version 1.2020 is also used $(56,110)$. The further identification of risk factors associated with AEs during ICB is critical for the prevention and early management of IRAEs. In addition, there are currently limited data on the efficacy and safety of ICIs in special patient populations including older patients, patients with hepatitis virus 
or HIV infections, and those with poor performance status, brain or liver metastases, or autoimmune diseases $(111,112)$. These patient groups are often excluded from clinical trials and in China further data are required to support the establishment of treatment guidelines for such cohorts of patients with NSCLC.

\section{DISCUSSION}

Despite recent advances in the treatment of NSCLC using targeted therapies and immunotherapies, NSCLC remains the leading cause of cancer-related death in China. Therefore, novel agents and combination treatment strategies are urgently required to improve the survival outcomes of patients with advanced NSCLC. ICIs have revolutionized the treatment of NSCLC and other solid malignancies in China and worldwide. Clinical data suggest that pembrolizumab is a promising immunotherapeutic agent for the first-line treatment of patients with advanced NSCLC and has the most NMPAapproved indications. Notably, pembrolizumab is the only ICI providing an impressive 5-year survival rate in the first-line treatment of advanced NSCLC. In China, pembrolizumab has gained regulatory approval for use as the first-line treatment for NSCLC, either as monotherapy or in combination with chemotherapy. As numerous other domestic and imported ICIs are under extensive clinical investigation as monotherapy or combination therapy, more options will become available for the treatment of Chinese patients with advanced NSCLC.

Additionally, PD-L1 IHC 22C3 pharmDx is currently the only licensed NSCLC companion diagnostic in China, which could aid in selecting appropriate patients for pembrolizumab treatment and optimize the pembrolizumab regimen to

\section{REFERENCES}

1. GLOBOCAN 2020: Estimated Cancer Incidence, Mortality and Prevalence Worldwide in 2020 (2020). Available at: http://globocan.iarc.fr/Pages/fact_ sheets_cancer.aspx.

2. Cao M, Chen W. Epidemiology of Lung Cancer in China. Thorac Cancer (2019) 10(1):3-7. doi: 10.1111/1759-7714.12916

3. Chai Q, Shen Y, Du J, Zhu J, Wu B. Economic Burden of Patients With Advanced Non-Small-Cell Lung Cancer Receiving Nivolumab Versus Chemotherapy in China. Immunotherapy (2020) 12(4):245-54. doi: 10.2217/imt-2020-0030

4. Wan N, Zhang TT, Hua SH, Lu ZL, Ji B, Li LX, et al. Cost-Effectiveness Analysis of Pembrolizumab Plus Chemotherapy With PD-L1 Test for the First-Line Treatment of NSCLC. Cancer Med (2020) 9(5):1683-93. doi: $10.1002 / \mathrm{cam} 4.2793$

5. Jiang Y, Wang X. Cost-Effectiveness Analysis of Pembrolizumab Plus Standard Chemotherapy Versus Chemotherapy Alone for First-Line Treatment of Metastatic Non-Squamous Non-Small-Cell Lung Cancer in China. Eur J Hosp Pharm (2020). doi: 10.1136/ejhpharm-2020-002208

6. Ding H, Xin W, Tong Y, Sun J, Xu G, Ye Z, et al. Cost Effectiveness of Immune Checkpoint Inhibitors for Treatment of Non-Small Cell Lung Cancer: A Systematic Review. PloS One (2020) 15(9):e0238536. doi: 10.1371/ journal.pone. 0238536

7. Feng RM, Zong YN, Cao SM, Xu RH. Current Cancer Situation in China: Good or Bad News From the 2018 Global Cancer Statistics? Cancer Commun (Lond) (2019) 39(1):22. doi: 10.1186/s40880-019-0368-6

8. Barta JA, Powell CA, Wisnivesky JP. Global Epidemiology of Lung Cancer. Ann Glob Health (2019) 85(1):8. doi: 10.5334/aogh.2419 maximize its clinical benefits. This review provides an in-depth insight into recent advances in NSCLC immunotherapy and discusses future perspectives on the use of ICIs for the first-line treatment of NSCLC in China. As such, this and future comprehensive reviews of current and emerging immunotherapies for the first-line treatment of NSCLC are pivotal for the optimal management of NSCLC in China and for maximizing the clinical efficacy of ICIs in treatment-naïve patients with advanced NSCLC.

\section{AUTHOR CONTRIBUTIONS}

AX, JW, and CZ provided the concept for the review, and also contributed substantive suggestions for revision or critically reviewed subsequent iterations of the manuscript. All authors reviewed and approved the final version of the paper and agree to be accountable for all aspects of the work in ensuring that questions related to the accuracy or integrity of any part of the work are appropriately investigated and resolved.

\section{FUNDING}

This review was funded by MSD China.

\section{ACKNOWLEDGMENTS}

Editorial assistance was provided by Christos Evangelou $\mathrm{PhD}$ and Jake Burrell PhD (Rude Health Consulting). Editorial support for this manuscript was funded for by MSD China.

9. Huang Z, Su W, Lu T, Wang Y, Dong Y, Qin Y, et al. First-Line ImmuneCheckpoint Inhibitors in Non-Small Cell Lung Cancer: Current Landscape and Future Progress. Front Pharmacol (2020) 11:578091. doi: 10.3389/ fphar.2020.578091

10. Molina JR, Yang P, Cassivi SD, Schild SE, Adjei AA. Non-Small Cell Lung Cancer: Epidemiology, Risk Factors, Treatment, and Survivorship. Mayo Clin Proc (2008) 83(5):584-94. doi: 10.1016/S0025-6196(11)60735-0

11. Zhou C. Lung Cancer Molecular Epidemiology in China: Recent Trends. Transl Lung Cancer Res (2014) 3(5):270-9. doi: 10.3978/j.issn.22186751.2014.09.01

12. Wang P, Zou J, Wu J, Zhang C, Ma C, Yu J, et al. Clinical Profiles and Trend Analysis of Newly Diagnosed Lung Cancer in a Tertiary Care Hospital of East China During 2011-2015. J Thorac Dis (2017) 9(7):1973-9. doi: 10.21037/jtd.2017.06.102

13. Zhang N, Tu J, Wang X, Chu Q. Programmed Cell Death-1/Programmed Cell Death Ligand-1 Checkpoint Inhibitors: Differences in Mechanism of Action. Immunotherapy (2019) 11(5):429-41. doi: 10.2217/imt-2018-0110

14. Azoury SC, Straughan DM, Shukla V. Immune Checkpoint Inhibitors for Cancer Therapy: Clinical Efficacy and Safety. Curr Cancer Drug Targets (2015) 15(6):452-62. doi: 10.2174/156800961506150805145120

15. Shi Y, Sun Y. Medical Management of Lung Cancer: Experience in China. Thorac Cancer (2015) 6(1):10-6. doi: 10.1111/1759-7714.12168

16. Tan WL, Chua KLM, Lin CC, Lee VHF, Tho LM, Chan AW, et al. Asian Thoracic Oncology Research Group Expert Consensus Statement on Optimal Management of Stage III NSCLC. J Thorac Oncol (2020) 15 (3):324-43. doi: $10.1016 /$ j.jtho.2019.10.022

17. Zhou C, Wu YL, Chen G, Liu X, Zhu Y, Lu S, et al. BEYOND: A Randomized, Double-Blind, Placebo-Controlled, Multicenter, Phase III 
Study of First-Line Carboplatin/Paclitaxel Plus Bevacizumab or Placebo in Chinese Patients With Advanced or Recurrent Nonsquamous Non-SmallCell Lung Cancer. J Clin Oncol (2015) 33(19):2197-204. doi: 10.1200/ JCO.2014.59.4424

18. Liang JL, Ren XC, Lin Q. Treating Advanced Non-Small-Cell Lung Cancer in Chinese Patients: Focus on Icotinib. Onco Targets Ther (2014) 7:761-70. doi: $10.2147 / O T T . S 49233$

19. Patil T, Simons E, Mushtaq R, Pacheco JM, Doebele RC, Bowles DW. Targeted Therapies for ROS1-Rearranged Non-Small Cell Lung Cancer. Drugs Today (Barcelona Spain 1998) (2019) 55(10):641-52. doi: 10.1358/ dot.2019.55.10.3030646

20. Takano N, Ariyasu R, Koyama J, Sonoda T, Saiki M, Kawashima Y, et al. Improvement in the Survival of Patients With Stage IV Non-Small-Cell Lung Cancer: Experience in a Single Institutional 1995-2017. Lung Cancer (2019) 131:69-77. doi: 10.1016/j.lungcan.2019.03.008

21. Hardtstock F, Myers D, Li T, Cizova D, Maywald U, Wilke T, et al. RealWorld Treatment and Survival of Patients With Advanced Non-Small Cell Lung Cancer: A German Retrospective Data Analysis. BMC Cancer (2020) 20(1):260. doi: 10.1186/s12885-020-06738-z

22. Xing P, Wang H, Yang S, Han X, Sun Y, Shi Y. Therapeutic Cancer Vaccine: Phase I Clinical Tolerance Study of Hu-rhEGF-Rp64k/Mont in Patients With Newly Diagnosed Advanced Non-Small Cell Lung Cancer. BMC Immunol (2018) 19(1):14. doi: 10.1186/s12865-018-0249-9

23. Mi D, Ren W, Yang K. Adoptive Immunotherapy With Interleukin-2 \& Induced Killer Cells in Non-Small Cell Lung Cancer: A Systematic Review \& Meta-Analysis. Indian J Med Res (2016) 143(Supplement):S1-S10. doi: 10.4103/0971-5916.191738

24. Lin M, Luo H, Liang S, Chen J, Liu A, Niu L, et al. Pembrolizumab Plus Allogeneic NK Cells in Advanced Non-Small Cell Lung Cancer Patients. J Clin Invest (2020) 130(5):2560-9. doi: 10.1172/JCI132712

25. Xiao Z, Wang CQ, Zhou MH, Li NN, Liu SY, He YJ, et al. Clinical Efficacy and Safety of CIK Plus Radiotherapy for Lung Cancer: A Meta-Analysis of 16 Randomized Controlled Trials. Int Immunopharmacol (2018) 61:363-75. doi: 10.1016/j.intimp.2018.06.012

26. Xiao Z, Wang CQ, Feng JH, Zhou MH, Wang YZ, Li NN, et al. Effectiveness and Safety of Chemotherapy With Cytokine-Induced Killer Cells in NonSmall Cell Lung Cancer: A Systematic Review and Meta-Analysis of 32 Randomized Controlled Trials. Cytotherapy (2019) 21(2):125-47. doi: 10.1016/j.jcyt.2018.10.011

27. Wu YL, Wang CL, Liao ML, Guan ZZ, Gao CY, Lu S, et al. A Consensus on Immunotherapy From the 2017 Chinese Lung Cancer Summit Expert Panel. Transl Lung Cancer Res (2018) 7(3):428-36. doi: 10.21037/tlcr.2018.04.15

28. Xia L, Liu Y, Wang Y. PD-1/PD-L1 Blockade Therapy in Advanced NonSmall-Cell Lung Cancer: Current Status and Future Directions. Oncologist (2019) 24(Suppl 1):S31-41. doi: 10.1634/theoncologist.2019-IO-S1-s05

29. Cui P, Li R, Huang Z, Wu Z, Tao H, Zhang S, et al. Comparative Effectiveness of Pembrolizumab vs. Nivolumab in Patients With Recurrent or Advanced NSCLC. Sci Rep (2020) 10(1):13160. doi: 10.1038/s41598-02070207-7

30. Wu DW, Huang HY, Tang Y, Zhao Y, Yang ZM, Wang J, et al. Clinical Development of Immuno-Oncology in China. Lancet Oncol (2020) 21 (8):1013-6. doi: 10.1016/S1470-2045(20)30329-6

31. Zhang B, Song Y, Fu Y, Zhu B, Wang B, Wang J. Current Status of the Clinical Use of PD-1/PD-L1 Inhibitors: A Questionnaire Survey of Oncologists in China. BMC Cancer (2020) 20(1):86. doi: 10.1186/s12885020-6583-3

32. Study Evaluating the Safety, Tolerability, and Initial Efficacy of Recombinant Human Anti-T-Cell Immunoreceptor With Ig and ITIM Domains (TIGIT) Monoclonal Antibody Injection (IBI939) in Subjects With Advanced Malignant Tumors . Available at: https://clinicaltrials.gov/ct2/show/ NCT04353830.

33. Gadgeel S, Rodríguez-Abreu D, Speranza G, Esteban E, Felip E, Dómine M, et al. Updated Analysis From KEYNOTE-189: Pembrolizumab or Placebo Plus Pemetrexed and Platinum for Previously Untreated Metastatic Nonsquamous Non-Small-Cell Lung Cancer. J Clin Oncol (2020) 38 (14):1505-17. doi: 10.1200/JCO.19.03136

34. Mok TSK, Wu YL, Kudaba I, Kowalski DM, Cho BC, Turna HZ, et al. Pembrolizumab Versus Chemotherapy for Previously Untreated, PD-L1-
Expressing, Locally Advanced or Metastatic Non-Small-Cell Lung Cancer (KEYNOTE-042): A Randomised, Open-Label, Controlled, Phase 3 Trial. Lancet (2019) 393(10183):1819-30. doi: 10.1016/S0140-6736(18)32409-7

35. Cho BC, Wu Y, Lopes G, Kudaba I, Kowalski DM, Turna HZ, et al. FP13.04 KEYNOTE-042 3-Year Survival Update: 11 Pembrolizumab vs PlatinumBased Chemotherapy for PD-L1+ Locally Advanced/Metastatic NSCLC. J Thorac Oncol (2021) 16(3):S225-S6. doi: 10.1016/j.jtho.2021.01.143

36. Wu YL, Zhang L, Fan Y, Zhou J, Zhou Q, Li W, et al. Randomized Clinical Trial of Pembrolizumab Versus Chemotherapy for Previously Untreated Chinese Patients With PD-L1-Positive Locally Advanced or Metastatic NonSmall-Cell Lung Cancer: KEYNOTE-042 China Study. Int J Cancer (2020) 148(9):2313-20. doi: 10.1002/ijc.33399

37. Paz-Ares L, Vicente D, Tafreshi A, Robinson A, Soto Parra H, Mazières J, et al. A Randomized, Placebo-Controlled Trial of Pembrolizumab Plus Chemotherapy in Patients With Metastatic Squamous NSCLC: ProtocolSpecified Final Analysis of KEYNOTE-407. J Thorac Oncol (2020) 15 (10):1657-69. doi: 10.1016/j.jtho.2020.06.015

38. Robinson AG, Vicente D, Tafreshi A, Parra HS, Mazieres J, Cicin I, et al. 97o First-Line Pembrolizumab Plus Chemotherapy for Patients With Advanced Squamous NSCLC: 3-Year Follow-Up From KEYNOTE-407. J Thorac Oncol (2021) 16(4):S748-S9. doi: 10.1016/S1556-0864(21)01939-0

39. Antonia SJ, Villegas A, Daniel D, Vicente D, Murakami S, Hui R, et al. Durvalumab After Chemoradiotherapy in Stage III Non-Small-Cell Lung Cancer. N Engl J Med (2017) 377(20):1919-29. doi: 10.1056/ NEJMoa1709937

40. Herbst RS, Giaccone G, de Marinis F, Reinmuth N, Vergnenegre A, Barrios $\mathrm{CH}$, et al. Atezolizumab for First-Line Treatment of PD-L1-Selected Patients With NSCLC. N Engl J Med (2020) 383(14):1328-39. doi: 10.1056/ NEJMoa1917346

41. Jassem J, de Marinis F, Giaccone G, Vergnenegre A, Barrios CH, Morise M, et al. Updated Overall Survival Analysis From IMpower110: Atezolizumab Versus Platinum-Based Chemotherapy in Treatment-Naive PD-L1-Selected Non-Small Cell Lung Cancer. J Thorac Oncol (2021) 16(11):1872-82. doi: 10.1016/j.jtho.2021.06.019

42. Socinski MA, Jotte RM, Cappuzzo F, Orlandi F, Stroyakovskiy D, Nogami N, et al. Atezolizumab for First-Line Treatment of Metastatic Nonsquamous NSCLC. N Engl J Med (2018) 378(24):2288-301. doi: 10.1056/ NEJMoa1716948

43. Socinski MA, Mok TS, Nishio M, Jotte RM, Cappuzzo F, Orlandi F, et al. Abstract CT216: IMpower150 Final Analysis: Efficacy of Atezolizumab (Atezo) + Bevacizumab (Bev) and Chemotherapy in First-Line (1L) Metastatic Nonsquamous (Nsq) Non-Small Cell Lung Cancer (NSCLC) Across Key Subgroups. Cancer Res (2020) 80(16 Supplement):CT216-CT. doi: 10.1158/1538-7445.AM2020-CT216

44. West H, McCleod M, Hussein M, Morabito A, Rittmeyer A, Conter HJ, et al. Atezolizumab in Combination With Carboplatin Plus Nab-Paclitaxel Chemotherapy Compared With Chemotherapy Alone as First-Line Treatment for Metastatic Non-Squamous Non-Small-Cell Lung Cancer (IMpower130): A Multicentre, Randomised, Open-Label, Phase 3 Trial. Lancet Oncol (2019) 20(7):924-37. doi: 10.1016/S1470-2045(19)30167-6

45. Nasser NJ, Gorenberg M, Agbarya A. First Line Immunotherapy for NonSmall Cell Lung Cancer. Pharmaceuticals (Basel) (2020) 13(11):373. doi: 10.3390/ph13110373

46. Sezer A, Kilickap S, Gümüş M, Bondarenko I, Özgüroğlu M, Gogishvili M, et al. Cemiplimab Monotherapy for First-Line Treatment of Advanced NonSmall-Cell Lung Cancer With PD-L1 of at Least 50\%: A Multicentre, OpenLabel, Global, Phase 3, Randomised, Controlled Trial. Lancet (2021) 397 (10274):592-604. doi: 10.1016/S0140-6736(21)00228-2

47. Hellmann MD, Paz-Ares L, Bernabe Caro R, Zurawski B, Kim SW, Carcereny Costa E, et al. Nivolumab Plus Ipilimumab in Advanced NonSmall-Cell Lung Cancer. N Engl J Med (2019) 381(21):2020-31. doi: 10.1056/NEJMoa1910231

48. Zhou C, Chen G, Huang Y, Zhou J, Lin L, Feng J, et al. Camrelizumab Plus Carboplatin and Pemetrexed Versus Chemotherapy Alone in Chemotherapy-Naive Patients With Advanced Non-Squamous NonSmall-Cell Lung Cancer (CameL): A Randomised, Open-Label, Multicentre, Phase 3 Trial. Lancet Respir Med (2021) 9(3):305-14. doi: $10.1016 /$ S2213-2600(20)30365-9 
49. Zhou C, Chen G, Huang Y, Zhou J, Lin L, Feng J, et al. OA04.03 A Randomized Phase 3 Study of Camrelizumab Plus Chemotherapy as 1st Line Therapy for Advanced/Metastatic Non-Squamous Non-Small Cell Lung Cancer. J Thorac Oncol (2019) 14(10):S215-S6. doi: 10.1016/ j.jtho.2019.08.425

50. Wang J, Lu S, Yu X, Hu Y, Sun Y, Wang Z, et al. Tislelizumab Plus Chemotherapy vs Chemotherapy Alone as First-Line Treatment for Advanced Squamous Non-Small-Cell Lung Cancer: A Phase 3 Randomized Clinical Trial. JAMA Oncol (2021) 7(5):709-17. doi: 10.1001/ jamaoncol.2021.0366

51. Wang J, Yu X, Lu S, Hu Y, Sun Y, Wang Z, et al. Phase III Study of Tislelizumab Plus Chemotherapy vs Chemotherapy Alone as First-Line (1L) Treatment for Advanced Squamous Non-Small Cell Lung Cancer (Sq NSCLC). J Clin Oncol (2020) 38(15_suppl):9554-. doi: 10.1200/ JCO.2020.38.15_suppl.9554

52. Lu S, Wang J, Yu Y, Yu X, Hu Y, Ai X, et al. Tislelizumab Plus Chemotherapy as First-Line Treatment for Locally Advanced or Metastatic Nonsquamous Non-Small Cell Lung Cancer (RATIONALE 304): A Randomized Phase 3 Trial. J Thorac Oncol (2021) 16(9):1512-22. doi: 10.1016/j.jtho.2021.05.005

53. Yang Y, Wang Z, Fang J, Yu Q, Han B, Cang S, et al. Efficacy and Safety of Sintilimab Plus Pemetrexed and Platinum as First-Line Treatment for Locally Advanced or Metastatic Nonsquamous NSCLC: A Randomized, Double-Blind, Phase 3 Study (Oncology Program by InnovENT Anti-PD-111). J Thorac Oncol (2020) 15(10):1636-46. doi: 10.1016/j.jtho.2020.07.014

54. Zhou C, Wu L, Fan Y, Wang Z, Liu L, Chen G, et al. Sintilimab Plus Platinum and Gemcitabine as First-Line Treatment for Advanced or Metastatic Squamous NSCLC: Results From a Randomized, Double-Blind, Phase 3 Trial (ORIENT-12). J Thorac Oncol (2021) 16(9):1501-11. doi: 10.1016/j.jtho.2021.04.011

55. Association TPCoCA-C, Oncology ECoPoCSoC and Oncology ECoNSCLCoCSoC. [Expert Consensus on PD-L1 Expression Testing in NonSmall-Cell Lung Cancer in China]. Zhonghua Zhong Liu Za Zhi (2020) 42 (7):513-21. doi: 10.3760/cma.j.cn112152-20200313-00202

56. Chinese Anti-Cancer Association LnCSGoCoO, Cancer CSoL and Consensus EGoP-LT. [Chinese Expert Consensus on Standards of PD-L1 Immunohistochemistry Testing for Non-Small Cell Lung Cancer]. Zhongguo Fei Ai Za Zhi (2020) 23(9):733-40. doi: 10.3779/j.issn.10093419.2020.101.43

57. Zhang L, Mai W, Jiang W, Geng Q. Sintilimab: A Promising Anti-Tumor PD-1 Antibody. Front Oncol (2020) 10:594558. doi: 10.3389/ fonc.2020.594558

58. Guo L, Wei R, Lin Y, Kwok HF. Clinical and Recent Patents Applications of PD-1/PD-L1 Targeting Immunotherapy in Cancer Treatment-Current Progress, Strategy, and Future Perspective. Front Immunol (2020) 11:1508. doi: 10.3389/fimmu.2020.01508

59. Wang W, Sun Q. Novel Targeted Drugs Approved by the NMPA and FDA in 2019. Signal Transduct Target Ther (2020) 5(1):65.

60. Reck M, Rodríguez-Abreu D, Robinson AG, Hui R, Csőszi T, Fülöp A, et al. Pembrolizumab Versus Chemotherapy for PD-L1-Positive Non-Small-Cell Lung Cancer. N Engl J Med (2016) 375(19):1823-33. doi: 10.1056/ NEJMoa1606774

61. Reck M, Rodríguez-Abreu D, Robinson AG, Hui R, Csőszi T, Fülöp A, et al. Five-Year Outcomes With Pembrolizumab Versus Chemotherapy for Metastatic Non-Small-Cell Lung Cancer With PD-L1 Tumor Proportion Score $\geq$ 50\%. J Clin Oncol (2021) 39(21):2339-49. doi: 10.1200/JCO.21.00174

62. Carbone DP, Reck M, Paz-Ares L, Creelan B, Horn L, Steins M, et al. FirstLine Nivolumab in Stage IV or Recurrent Non-Small-Cell Lung Cancer. N Engl J Med (2017) 376(25):2415-26. doi: 10.1056/NEJMoa1613493

63. Cheng Y, Zhang L, Hu J, Wang D, Hu C, Zhou J, et al. Keynote-407 China Extension Study: Pembrolizumab (Pembro) Plus Chemotherapy in Chinese Patients With Metastatic Squamous NSCLC. Ann Oncol (2019) 30:ix201ix2. doi: 10.1093/annonc/mdz446

64. Zhou C, Ren S, Chen J, Xu X, Cheng Y, Chen G, et al. 96o Camrelizumab or Placebo Plus Carboplatin and Paclitaxel as First-Line Treatment for Advanced Squamous NSCLC (CameL-Sq): A Randomized, Double-Blind, Multicenter, Phase III Trial. J Thorac Oncol (2021) 16(4):S748. doi: 10.1016/ S1556-0864(21)01938-9
65. Zhou C, Wang Z, Sun Y, Cao L, Ma Z, Wu R, et al. LBA4 GEMSTONE-302: A Phase III Study of Platinum-Based Chemotherapy (Chemo) With Placebo or CS1001, an Anti-PDL1 Antibody, for First-Line (1L) Advanced NonSmall Cell Lung Cancer (NSCLC). Ann Oncol (2020) 31:S1386. doi: 10.1016/ j.annonc.2020.10.368

66. Boyer M, Şendur MAN, Rodríguez-Abreu D, Park K, Lee DH, Çiçin I, et al. Pembrolizumab Plus Ipilimumab or Placebo for Metastatic Non-Small-Cell Lung Cancer With PD-L1 Tumor Proportion Score $\geq 50 \%$ : Randomized, Double-Blind Phase III KEYNOTE-598 Study. J Clin Oncol (2021) 39 (21):2327-38. doi: 10.1200/JCO.20.03579

67. Liu SY, Wu YL. Tislelizumab: An Investigational Anti-PD-1 Antibody for the Treatment of Advanced Non-Small Cell Lung Cancer (NSCLC). Expert Opin Investig Drugs (2020) 29(12):1355-64. doi: 10.1080/ 13543784.2020.1833857

68. Qu J, Wang L, Jiang M, Zhao D, Wang Y, Zhang F, et al. A Review About Pembrolizumab in First-Line Treatment of Advanced NSCLC: Focus on KEYNOTE Studies. Cancer Manag Res (2020) 12:6493-509. doi: 10.2147/ CMAR.S257188

69. Liu SY, Wu YL. Ongoing Clinical Trials of PD-1 and PD-L1 Inhibitors for Lung Cancer in China. J Hematol Oncol (2017) 10(1):136. doi: 10.1186/ s13045-017-0506-z

70. Garon EB, Hellmann MD, Rizvi NA, Carcereny E, Leighl NB, Ahn MJ, et al. Five-Year Overall Survival for Patients With Advanced Non-Small-Cell Lung Cancer Treated With Pembrolizumab: Results From the Phase I KEYNOTE-001 Study. J Clin Oncol (2019) 37(28):2518-27. doi: 10.1200/ JCO.19.00934

71. Pai-Scherf L, Blumenthal GM, Li H, Subramaniam S, Mishra-Kalyani PS, He K, et al. FDA Approval Summary: Pembrolizumab for Treatment of Metastatic Non-Small Cell Lung Cancer: First-Line Therapy and Beyond. Oncologist (2017) 22(11):1392-9. doi: 10.1634/theoncologist.2017-0078

72. FDA Expands Pembrolizumab Indication for First-Line Treatment of NSCLC (TPS $\geq 1 \%$ ). U.S: Food and Drug Administration (2019). Available at: https:// www.fda.gov/drugs/fda-expands-pembrolizumab-indication-first-linetreatment-nsclc-tps-1.

73. Jassem J, Herbst RS, Marinis FD, Cadranel J, Csőszi T, Isla D, et al. IMpower110: Clinical Safety in a Phase III Study of Atezolizumab (Atezo) Monotherapy (Mono) vs Platinum-Based Chemotherapy (Chemo) in FirstLine Non-Small Cell Lung Cancer (NSCLC). J Clin Oncol (2020) 38 (15_suppl):e21623-e. doi: 10.1200/JCO.2020.38.15_suppl.e21623

74. Herbst R, Marinis FD, Giaccone G, Reinmuth N, Vergnenegre A, Barrios C, et al. O81 IMpower110: Interim Overall Survival (OS) Analysis of a Phase III Study of Atezolizumab (ATEZO) Monotherapy vs Platinum-Based Chemotherapy (CHEMO) as First-Line (1L) Treatment in PD-L1-selected NSCLC. J ImmunoTher Cancer (2020) 8(Suppl 1):A1-A. doi: 10.1136/ LBA2019.1

75. Peng J, Hamanishi J, Matsumura N, Abiko K, Murat K, Baba T, et al. Chemotherapy Induces Programmed Cell Death-Ligand 1 Overexpression via the Nuclear Factor- $\mathrm{kb}$ to Foster an Immunosuppressive Tumor Microenvironment in Ovarian Cancer. Cancer Res (2015) 75(23):5034-45. doi: 10.1158/0008-5472.CAN-14-3098

76. Zhang P, Ma Y, Lv C, Huang M, Li M, Dong B, et al. Upregulation of Programmed Cell Death Ligand 1 Promotes Resistance Response in NonSmall-Cell Lung Cancer Patients Treated With Neo-Adjuvant Chemotherapy. Cancer Sci (2016) 107(11):1563-71. doi: 10.1111/cas.13072

77. Anyaegbu CC, Lake RA, Heel K, Robinson BW, Fisher SA. Chemotherapy Enhances Cross-Presentation of Nuclear Tumor Antigens. PloS One (2014) 9 (9):e107894. doi: 10.1371/journal.pone.0107894

78. Wang YJ, Fletcher R, Yu J, Zhang L. Immunogenic Effects of ChemotherapyInduced Tumor Cell Death. Genes Dis (2018) 5(3):194-203. doi: 10.1016/ j.gendis.2018.05.003

79. Li JY, Duan XF, Wang LP, Xu YJ, Huang L, Zhang TF, et al. Selective Depletion of Regulatory T Cell Subsets by Docetaxel Treatment in Patients With Nonsmall Cell Lung Cancer. J Immunol Res (2014) 2014:286170. doi: $10.1155 / 2014 / 286170$

80. Awad MM, Gadgeel SM, Borghaei H, Patnaik A, Yang JC, Powell SF, et al. Long-Term Overall Survival From KEYNOTE-021 Cohort G: Pemetrexed and Carboplatin With or Without Pembrolizumab as First-Line Therapy for 
Advanced Nonsquamous NSCLC. J Thorac Oncol (2021) 16(1):162-8. doi: 10.1016/j.jtho.2020.09.015

81. Borghaei H, Langer CJ, Paz-Ares L, Rodríguez-Abreu D, Halmos B, Garassino MC, et al. Pembrolizumab Plus Chemotherapy Versus Chemotherapy Alone in Patients With Advanced Non-Small Cell Lung Cancer Without Tumor PD-L1 Expression: A Pooled Analysis of 3 Randomized Controlled Trials. Cancer (2020) 126(22):4867-77. doi: $10.1002 / \mathrm{cncr} .33142$

82. Langer CJ, Gadgeel SM, Borghaei H, Papadimitrakopoulou VA, Patnaik A, Powell SF, et al. Carboplatin and Pemetrexed With or Without Pembrolizumab for Advanced, Non-Squamous Non-Small-Cell Lung Cancer: A Randomised, Phase 2 Cohort of the Open-Label KEYNOTE021 Study. Lancet Oncol (2016) 17(11):1497-508. doi: 10.1016/S1470-2045 (16)30498-3

83. Zhou C, Wang J, Bu H, Wang B, Han B, Lu Y, et al. [Chinese Experts Consensus on Immune Checkpoint Inhibitors for Non-Small Cell Lung Cancer (2019 Version)]. Zhongguo Fei Ai Za Zhi (2020) 23(2):65-76. doi: 10.3779/j.issn.1009-3419.2020.02.01

84. Paz-Ares L, Ciuleanu T-E, Cobo M, Schenker M, Zurawski B, Menezes J, et al. First-Line Nivolumab Plus Ipilimumab Combined With Two Cycles of Chemotherapy in Patients With Non-Small-Cell Lung Cancer (CheckMate 9LA): An International, Randomised, Open-Label, Phase 3 Trial. Lancet Oncol (2021) 22(2):198-211. doi: 10.1016/S1470-2045(20)30641-0

85. Innovent and Lilly Jointly Announce the Approval of TYVYT ${ }^{\circledR}$ (Sintilimab Injection) by China NMPA in Combination With Pemetrexed and Platinum Chemotherapy as First-Line Therapy for Nonsquamous Non-Small Cell Lung Cancer. [Press Release]. (2021). Available at: https://www.innoventbio. com/InvestorsAndMedia/PressReleaseDetail?key=233.

86. Innovent and Lilly Jointly Announce the China NMPA Approval of TYVYT $^{\circledR}$ (Sintilimab Injection) in Combination With Gemcitabine and Platinum Chemotherapy as First-Line Therapy for People With Squamous Non-Small Cell Lung Cancer [Press Release]. Innovent Biol (2021). Available at: https://www.innoventbio.com/InvestorsAndMedia/PressReleaseDetail? $k e y=249$.

87. Incorvaia L, Fanale D, Badalamenti G, Barraco N, Bono M, Corsini LR, et al. Programmed Death Ligand 1 (PD-L1) as a Predictive Biomarker for Pembrolizumab Therapy in Patients With Advanced Non-Small-Cell Lung Cancer (NSCLC). Adv Ther (2019) 36(10):2600-17. doi: 10.1007/s12325019-01057-7

88. Torous VF, Rangachari D, Gallant BP, Shea M, Costa DB, VanderLaan PA. PD-L1 Testing Using the Clone 22C3 pharmDx Kit for Selection of Patients With Non-Small Cell Lung Cancer to Receive Immune Checkpoint Inhibitor Therapy: Are Cytology Cell Blocks a Viable Option? J Am Soc Cytopathol (2018) 7(3):133-41. doi: 10.1016/j.jasc.2018.02.003

89. Vennapusa B, Baker B, Kowanetz M, Boone J, Menzl I, Bruey JM, et al. Development of a PD-L1 Complementary Diagnostic Immunohistochemistry Assay (SP142) for Atezolizumab. Appl Immunohistochem Mol Morphol (2019) 27(2):92-100. doi: 10.1097/PAI.0000000000000594

90. Chen M, Li Q, Xu Y, Zhao J, Zhang L, Wei L, et al. Immunotherapy as Second-Line Treatment and Beyond for Non-Small Cell Lung Cancer in a Single Center of China: Outcomes, Toxicities, and Clinical Predictive Factors From a Real-World Retrospective Analysis. Thorac Cancer (2020) 11 (7):1955-62. doi: 10.1111/1759-7714.13488

91. Guo H, Li L, Cui J. Advances and Challenges in Immunotherapy of Small Cell Lung Cancer. Chin J Cancer Res (2020) 32(1):115-28. doi: 10.21147/ j.issn.1000-9604.2020.01.13

92. Hegde PS, Chen DS. Top 10 Challenges in Cancer Immunotherapy. Immunity (2020) 52(1):17-35. doi: 10.1016/j.immuni.2019.12.011

93. Song P, Yang D, Cui X, Wang H, Si X, Zhang X, et al. NLCIPS: Non-Small Cell Lung Cancer Immunotherapy Prognosis Score. Cancer Manag Res (2020) 12:5975-85. doi: 10.2147/CMAR.S257967

94. Yu Y, Zeng D, Ou Q, Liu S, Li A, Chen Y, et al. Association of Survival and Immune-Related Biomarkers With Immunotherapy in Patients With NonSmall Cell Lung Cancer: A Meta-Analysis and Individual Patient-Level Analysis. JAMA Netw Open (2019) 2(7):e196879. doi: 10.1001/ jamanetworkopen.2019.6879

95. Zhang Z, Yuan F, Chen R, Li Y, Ma J, Yan X, et al. Dynamics of Serum Tumor Markers Can Serve as a Prognostic Biomarker for Chinese
Advanced Non-Small Cell Lung Cancer Patients Treated With Immune Checkpoint Inhibitors. Front Immunol (2020) 11:1173. doi: 10.3389/ fimmu.2020.01173

96. Li Y, Zhang Z, Hu Y, Yan X, Song Q, Wang G, et al. Pretreatment Neutrophil-To-Lymphocyte Ratio (NLR) May Predict the Outcomes of Advanced Non-Small-Cell Lung Cancer (NSCLC) Patients Treated With Immune Checkpoint Inhibitors (ICIs). Front Oncol (2020) 10:654. doi: $10.3389 /$ fonc. 2020.00654

97. Zhang L, Bai L, Liu X, Liu Y, Li S, Liu J, et al. Factors Related to Rapid Progression of Non-Small Cell Lung Cancer in Chinese Patients Treated Using Single-Agent Immune Checkpoint Inhibitor Treatment. Thorac Cancer (2020) 11(5):1170-9. doi: 10.1111/1759-7714.13370

98. Song P, Cui X, Bai L, Zhou X, Zhu X, Zhang J, et al. Molecular Characterization of Clinical Responses to PD-1/PD-L1 Inhibitors in NonSmall Cell Lung Cancer: Predictive Value of Multidimensional Immunomarker Detection for the Efficacy of PD-1 Inhibitors in Chinese Patients. Thorac Cancer (2019) 10(5):1303-9. doi: 10.1111/1759-7714.13078

99. Wang XE, Wang YH, Zhou Q, Peng M, Zhang J, Chen M, et al. Immunomodulatory Effect of Lentinan on Aberrant $\mathrm{T}$ Subsets and Cytokines Profile in Non-Small Cell Lung Cancer Patients. Pathol Oncol Res (2020) 26(1):499-505. doi: 10.1007/s12253-018-0545-y

100. Qiu L, Zhao X, Shi W, Sun S, Zhang G, Sun Q, et al. Real-World Treatment Efficacy of Anti-Programmed Death-1 Combined With Anti-Angiogenesis Therapy in Non-Small Cell Lung Cancer Patients. Med (Baltimore) (2020) 99 (24):e20545. doi: 10.1097/MD.0000000000020545

101. Liang W, Guo M, Pan Z, Cai X, Li C, Zhao Y, et al. Association Between Certain Non-Small Cell Lung Cancer Driver Mutations and Predictive Markers for Chemotherapy or Programmed Death-Ligand 1 Inhibition. Cancer Sci (2019) 110(6):2014-21. doi: 10.1111/cas.14032

102. Xu Z, Li H, Dong Y, Cheng P, Luo F, Fu S, et al. Incidence and PD-L1 Expression of. Onco Targets Ther (2020) 13:6245-53. doi: 10.2147/ OTT.S241231

103. Hu XY, Zhang W, Hu Y, Zhang Y, Gong R, Liang JY, et al. A Meta-Analysis Reveals Prognostic Role of Programmed Death Ligand-1 in Asian Patients With Non-Small Cell Lung Cancer. J Huazhong Univ Sci Technol Med Sci (2016) 36(3):313-20. doi: 10.1007/s11596-016-1585-8

104. Jin Y, Shen X, Pan Y, Zheng Q, Chen H, Hu H, et al. Correlation Between PD-L1 Expression and Clinicopathological Characteristics of Non-Small Cell Lung Cancer: A Real-World Study of a Large Chinese Cohort. J Thorac Dis (2019) 11(11):4591-601. doi: 10.21037/jtd.2019.10.80

105. Xia H, Shen J, Hu F, Chen S, Huang H, Xu Y, et al. PD-L1 Over-Expression Is Associated With a Poor Prognosis in Asian Non-Small Cell Lung Cancer Patients. Clin Chim Acta (2017) 469:191-4. doi: 10.1016/j.cca.2017.02.005

106. Zhang XC, Cao X, Sun C, Xie Z, Guo JJ, Yang JJ, et al. Characterization of PD-L1 Expression in Chinese Non-Small Cell Lung Cancer Patients With PTEN Expression as a Means for Tissue Quality Screening. Cancer Immunol Immunother (2018) 67(3):471-81. doi: 10.1007/s00262-017-2098-4

107. Qiang Z, Yan H, Xin Z, Xiaoyan C, Shihong S, Yan J, et al. Clinicopathological and Molecular Characteristics Associated With PD-L1 Expression in NonSmall Cell Lung Cancer: A Large-Scale, Multi-Center, Real-World Study in China. J Cancer Res Clin Oncol (2021) 147(5):1547-56. doi: 10.1007/s00432020-03444-y.

108. Jiang H. Overview of Gefitinib in Non-Small Cell Lung Cancer: An Asian Perspective. Jpn J Clin Oncol (2009) 39(3):137-50. doi: 10.1093/jjco/hyn139

109. Gou LY, Wu YL. Prevalence of Driver Mutations in Non-Small-Cell Lung Cancers in the People's Republic of China. Lung Cancer (Auckl) (2014) 5:1-9. doi: 10.2147/LCTT.S40817

110. Thompson JA, Schneider BJ, Brahmer J, Andrews S, Armand P, Bhatia S, et al. Management of Immunotherapy-Related Toxicities, Version 1.2019. J Natl Compr Canc Netw (2019) 17(3):255-89. doi: 10.6004/jnccn.2019.0013

111. Ferrara R, Mezquita L, Auclin E, Chaput N, Besse B. Immunosenescence and Immunecheckpoint Inhibitors in Non-Small Cell Lung Cancer Patients: Does Age Really Matter? Cancer Treat Rev (2017) 60:60-8. doi: 10.1016/ j.ctrv.2017.08.003

112. Gounant V, Lavolé A, Quoix E. Ongoing Challenges of Using Immunotherapy in Special Populations: Poor Performance Status Patients, Elderly Patients, and People Living With HIV. Lung Cancer (2020) 145:715. doi: 10.1016/j.lungcan.2020.04.025 
Conflict of Interest: JW was employed by MSD China. CZ reports personal fees from Lily China, Sanofi, BI, Roche China, MSD, Qilu, Hengrui, Innovent Biologics, C-stone, LUYE Pharma, TopAlliance Biosciences Inc, Amoy Diagnostics, outside the submitted work.

The remaining author declares that the research was conducted in the absence of any commercial or financial relationships that could be construed as a potential conflict of interest.

The authors declare that this study received funding from MSD China. The funder had the following involvement in the study: developing the concept of the review, the writing of this article and the decision to submit it for publication.
Publisher's Note: All claims expressed in this article are solely those of the authors and do not necessarily represent those of their affiliated organizations, or those of the publisher, the editors and the reviewers. Any product that may be evaluated in this article, or claim that may be made by its manufacturer, is not guaranteed or endorsed by the publisher.

Copyright (c) 2021 Xiong, Wang and Zhou. This is an open-access article distributed under the terms of the Creative Commons Attribution License (CC BY). The use, distribution or reproduction in other forums is permitted, provided the original author(s) and the copyright owner(s) are credited and that the original publication in this journal is cited, in accordance with accepted academic practice. No use, distribution or reproduction is permitted which does not comply with these terms. 